Commentary

iMedPub Journals

www.imedpub.com

DOI: $10.21767 / 2572-5610.100041$

\section{Survey on Genetical Variation Among the Students}

\section{Abstract}

Human genetics is the study of inheritance as it occurs in human beings. Human genetics encompasses a variety of overlapping fields including: Classical genetics, cytogenetics, molecular genetics, biochemical genetics, genomics, population genetics, developmental genetics, clinical genetics, and genetic counselling. Genes can be the common factor of the qualities of most human inherited traits. Study of human genetics can be useful as it can answer questions about human nature, understand the diseases and development of effective disease treatment and understand genetics of human life. The aim of the study was to see the genetic variation among the students shown in their phenotype. In the present study Survey on Genetical Variation among the Students in AMET University campus, Chennai.

Keywords: Genetical variation; Phenotype; Population genetics
Vijayaraj $\mathbf{R}^{1,2 *}$, Nathiya $\mathrm{P}^{1}$ and Swarnakala $\mathrm{N}^{2}$

1 Department of Biotechnology, Karunya University, Coimbatore, Tamilnadu, India

2 Department of Marine Biotechnology, AMET University, Chennai, Tamilnadu, India

*Corresponding author: Dr. Vijayaraj Radha

$\equiv$ vijayrradha@gmail.com

Department of Marine Biotechnology, AMET University, Chennai-603112, Tamilnadu, India.

Tel: 04427472905

Citation: Vijayaraj R, Nathiya P, Swarnakala N (2018) Survey on Genetical Variation Among the Students. Insights Biomed. Vol.3 No.1:6

\section{Introduction}

This article describes only basic phenotype of genetically variation. This survey was conducted among 100 students of AMET University, Chennai. The aim of the study was to see the genetic variation among the students shown in their phenotype. Normally, due to the certain alleles which dominant than other alleles in the genes, that characteristic of the alleles is expressed in an individual. Therefore, we can see certain phenotype changes in an individual which is unique and makes them appear distinct from another individual.

\section{Methodology}

\section{Period of study}

This study was conducted in May - 2017.

\section{Data collection}

The primary data are those which are collected afresh and for the first time and those happen to be original in character. The major tool has used for collecting data in this study is an interview and questionnaire (Tables 1 and 2).

1. The questions regarding personal data.

2. The questions regarding the identification of Phenotype character.

\section{Source}

The source is the primary data.

\section{Questionnaire}

Name:

Register Number:

Department:

Gender: Male/Female

Table 1 Data collection by gender.

\begin{tabular}{|c|c|}
\hline Gender & No. of Respondents \\
\hline Male & 72 \\
\hline Female & 28 \\
\hline Total & 100 \\
\hline
\end{tabular}

Table 2 Data collection by age.

\begin{tabular}{|c|c|}
\hline Age & No. of Respondents \\
\hline $18-22$ & 37 \\
\hline $22-26$ & 63 \\
\hline Total & 100 \\
\hline
\end{tabular}




\section{What is your blood group?}
[ ] A [ ] B [ ] AB [] O

2. Rh factor of your blood group?

[] Positive [] Negative

3. Are you able to roll your tongue?

[] Yes [] No

4. What kind of thumb Impression you have?

[ ] Circular [ ] Arch

5. Presence of mid-digital hair on your ring finger?

[ ] Yes [] No

\section{What kind of Darwin's tubercle?}

[ ] Ear with in Darwin's Tubercle [ ] Ear without Darwin's Tubercle

\section{What kind of ear loop you have?}

[ ] Attached Ear Loop [ ] Non Attached Ear Loop

8. How is the pattern on your hair whorl?

[ ] Clock Wise Hair Whorl [ ] Counter Clock Wise Hair Whorl

9. What is your toe length (based on your roots pattern)?

[ ] Toes ranging from big toes longer (upper left)

[ ] Toes ranging from big toe shorter (lower right).

10. Do you have cheek dimples?

[] Yes [] No

\section{Results and Discussion}

In this questionnaire, the first question was what your blood

\section{References}

1 Ayme S (2000) Letter to human genetics journals. American Journal of Human Genetics 66: 747-748. group is most of the students were having ' $B$ ' blood group (42\%), ' $O$ ' blood group (29\%) and ' $A$ ' and 'AB' blood group most of the students are Rh positive (95\%) and rest of them Rh negative (5\%). The next question was that whether they are able to roll their tongue or not, $80 \%$ of students were able to roll their tongue whereas $20 \%$ could not.

The most important question was the thumb impression, as we can see in the present days that our thumb impression and finger prints are taken for allotting identity card 'Aadhar card' or when travelling in other countries, to identify the person or to create a database having their individual information.

Since our fingerprints or the thumb impression is unique and different from one another most of the students were having circular (70\%) thumb impression and arch (30\%). $85 \%$ of the students have mid-digital hair on their finger while $15 \%$ of them do not have. $92 \%$ of the students have ears without Darwin's tubercule while $8 \%$ has Darwin's tubercule. Most of the students have attached ear loop (70\%) and 30\% have non-attached ear loop.

When the students were asked the question how the pattern of your hair whorl is, $52 \%$ of the students were having counter clockwise hair whorl whereas $48 \%$ of them have clockwise hair whorl. $48 \%$ of them have toes ranging from big toes shorter whereas $52 \%$ of them were having toes from lower right and $48 \%$ of them were having toes ranging from big toe shorter upper left. $77 \%$ of the students have no check dimple while very few students (23\%) have check dimples [1-4].

\section{Conclusion}

Therefore, as the result majority of the students in our survey are of $\mathrm{Rh}(+)$ blood group, they have circular thumb impression, attached ear finger, counter clock wise hair whorl while mostly do not have Darwin's tubercle and check dimples.

2 Sandrini F, Stratakis C (2003) Clinical and molecular genetics of Carney complex. Mol Genet Metab 78: 83-92.

3 Duggan JM (2011) Blood transfusion: Old blood, new blood or no blood. Int Med J 41: 358-359.

4 Shankar R (2013) Blood. Blood 121: 866-866. 